\title{
Engendering Nationalism and National Identity through Sports and Education in the Peruvian School System within the Context of Globalization
}

\author{
Francisco Javier León Cannock \\ $\mathrm{PhD}$ student International Education and Entrepreneurship, University of the Incarnate Word, \\ San Antonio, Texas, United States \\ E-mail: fleoncan@student.uiwtx.edu
}

Accepted: July 02, 2012 Published: July 24, 2012

Doi:10.5296/jsr.v3i2.2138 URL: http://dx.doi.org/10.5296/jsr.v3i2.2138

\begin{abstract}
Peru has experienced an economic boom in the past decade. Poverty level has decreased from $23 \%$ in 2002 to $11.5 \%$ in 2009 . Nonetheless, access to education and job opportunities are still unequal amongst social classes, ethnic groups, and genders. A Peruvian born in the rural highlands is four times more likely to be impoverished, and three times more likely to not complete secondary education, than someone from Lima. These social differences do not contribute to the formation of a cohesive national identity. Therefore, Peruvian identity is at a standstill point between past historical economical debacle, dictators, and terrorism; and the yearning for further economical expansion, social integration, and cultural apogee. Thus, this article analyzes the role of sports development in the process of engendering national identity sentiments in Peruvian education within the context of globalization. The study concludes that the social, political, and economical unrest in Peru has delayed not only the nation's growth in the global scene but also the development of a cohesive national identity. However, the research supports that physical education and sports activities, under the umbrella of a globalized, integral, multicultural, and inclusive educational environment, can contribute to the further development of a more cohesive Peruvian national identity.
\end{abstract}

Keywords: Peru, national identity, globalization, education, sports development.

\section{Introduction}

Education can no longer be analyzed without considering globalization as a reorganizing force. The fast-pace, high-tech, electronic world is radically changing the way education is studied by continuously implementing different ways to transmit knowledge (Carnoy \& Rhoten, 2002). As information and knowledge are transmitted faster from one place to 
another, it is natural to find not only more diversity and pluralism, but also more conflict across communities (Weisner, 2009). According to analysts in international education, the individual does not have to give up his cultural background to integrate with the new culture and to develop a sense of national identity (Banks, 2008). Therefore, research in comparative education suggests that an inclusive approach to education within culturally diverse nations positively contributes to the development of national identity in the context of globalization (Crossley, 2008).

The effectiveness of sports education and outdoor activities in youth development is a multifaceted approach that ultimately intends to modify a child's behavior. According to recent studies in physical education and youth development, physical activity helps to develop a sense of responsibility and independence; psychological variables considered to be important in the process of forming a person's national identity (Schweize \& Hummel, 2008). Furthermore, sports can have a positive effect in education, and upon a society's growth. Therefore, sports activities are considered important elements to both the social and the economic development of nation-states (Ogi, 2005).

The purpose of this paper is to analyze the relationship between youth sports and the formation of national identity within the context of a globalized, multicultural world. In order to exemplify this phenomenon, this research describes the relationships amongst three of the most important variables by which national identity is engendered in Peru: history and society, early education, and sports. The inter-connectivity and interdependence of these variables serve as anthropological points of reference to better understand the process of national identity formation in today's Peru in the light of an educational tendency to adapt and to learn from the global environment.

1.1 Education and globalization: Learning from diversity and the formation of national identity in multicultural nations.

Education can no longer be studied without considering globalization as a restructuring force. This restructuring of theories and methodologies is the result of linking economic and social change to the ways societies develop and transmit knowledge in the technological world. The fast-pace, high-tech, electronic world is radically changing the way education is studied by continuously implementing different ways to transmit knowledge (Carnoy \& Rhoten, 2002). Carnoy's and Rhoten's theory describes the future interdependency of nation-states, where the success of a nation in the globalized world depends on its functional inter-connectivity with other systems.

Scholars in comparative education suggest that globalization is making the world smaller. As information and knowledge are transmitted faster from one place to another it is expectable to find not only more diversity and pluralism but also more conflict across communities. 
According to Weisner's (2009) research, “...these (cultural) processes, some of which organize diversity to produce

consensus, whereas others produce intrapsychic, intersubjective, and cross-cultural conflict." (p. 181) Weisner argues that, even within the context of extreme pluralism and conflict, cultural intermingling has a unifying effect amongst subculture.

Cultural intermingling and diversity are key factors within the field of comparative education. According to Banks (2008), comparative education, “...challenges the liberal assimilations conceptions of national identity and citizenship." (p.129). Banks, instead, believes that citizenship education, and the rhetoric behind the formation national identity, should be reformed to meet a nation's cultural diversity so that it includes the languages and traditions of the sub-cultures that shape it. Moreover, Banks argues that citizenship and citizenship education should be molded to equally embrace the cultural rights of citizens from diverse racial, linguistic, ethnic backgrounds. According to Banks' theory the individual does not have to give up his cultural background to integrate with the new culture and to develop a sense of national identity. On the contrary, he says that, " an effective and transformative citizenship education helps students to acquire the knowledge, skills, and values needed to function effectively within their communities, nation-states, and the world.” (p.130).

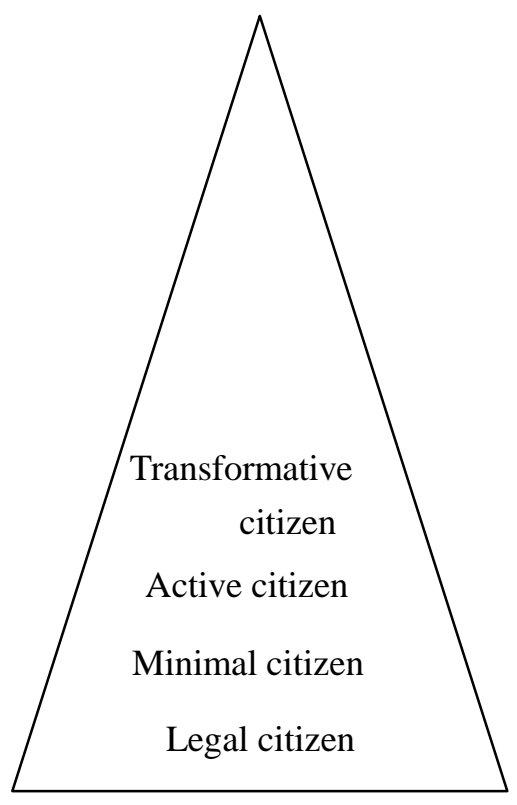

FIGURE 1. According to Banks (2008) theory of citizenship, there are four types of citizens. The first, the Legal Citizen, has rights and obligations to the nation-state but does not participate in the political system. The second, the Minimal Citizen, votes in the local and national elections and participates in conventional issues. The third, the Active Citizen, takes action beyond voting and plays an active role in society. The fourth, the Transformative Citizen, takes action beyond conventional issues, always trying to actualize values and moral principles beyond those of conventional authority. Examples of Transformative Citizens are 
Rosa Parks and Martin Luther King because of their proactive questioning of the social and political status-quo.

Transformative and democratic citizenship education not only foments cooperation and integration among diverse ethnic groups but also promotes positive interactions and relationships within multicultural environments (Banks, 2008). Banks developed a typology (see figure 1) aimed to help educators promote stronger citizenship feelings amongst their students. Banks' theory describes the four levels of citizenship maturity that can be found in society and thus how transformative education can help individuals, "to acquire the knowledge, values, and skills needed to become "deep citizens" (p.136)

\subsection{The importance of psychosocial development: Creating national identity and economic growth through physical education and sports}

Specialists in psychology suggest that the development of a child's personality evolves from the individual (self-consciousness and self-awareness) to the social (Schweize \& Hummel, 2008). The effectiveness of sports education and outdoor activities in youth development is a multifaceted approach that ultimately intends to modify a child's behavior. Research supports that outdoor education has a positive effect on children's self-esteem, interpersonal conduct, social behavior, awareness of body, and movement. According to Schweize and Hummel, outdoor and physical education, "promote[s] individual responsibility, strengthens independence and lend[s] further proof to the possible potential of adventure-based learning to enhance self-development and increase self-confidence" (p.147). Schweize and Hummel suggest that developing a sense of responsibility and independence is an important psychological basis in the process of forming a person's national identity.

Further research in education, sociology, and psychology also argue that physical education and sports can have the potential to promote positive social values. Flores and Zamora (2009) say that, "The decline in value systems is directly correlated to negative behaviors... the research confirms that both physical education and sports activity contribute to the construction of positive and socially acceptable behaviors" ( $p$ 134). These behaviors strengthen the will to reach a higher physical health, psychosocial balance, and, therefore, a higher quality of life (Flores \& Zamora, 2009).

Within that context, sports can have a positive effect in education and upon a society's growth. The sports industry is considered an important variable to the social and economic development of nation-states. Ogi (2005) analyzes the relationships between the sports industry and the world economy. He says “... the sports industry is rapidly expanding... and economically it remains one of the fastest growing" (p.43). Ogi states that physical education is vital to both an individual's and a society's well-balanced development. He indicates that, "sports can contribute too many forms of social, economic, and human development" (p.44). 


\subsection{From national identity to nationalism: The role of sports}

Nationalism is typically defined, although it may vary across cultures, as the sense of belonging to a nation. Nationality, however, is the legal term used by nation-states to refer to all the individuals born, or naturalized, in their territories (Gutek, 2006; Perez, 1999; Rottenbach \& Espinosa, 2010). These individuals are called citizens. Nation-states across societies create institutional structures to govern their people. These governments are responsible for the education of their citizens. Gutek (2006) says that, "schools are used to socialize the young in the political ideology, to maintain the nation-state's cultural traditions, and to reproduce them for further generations (p. 117.). According to Gutek, schools are one of the most important tools for a nation-state to maintain the social and political status-quo, to foster nationalism, and to develop national identity.

Early twentieth century American political institutions attempted to engender national identity sentiments in children by promoting the implementation of sporting events, the creation of playgrounds, the improvement of physical education programs and the popularization of physical activity in general (Gagen, 2004). The goal of this national initiative was to create a homogeneous American community in which immigrants assimilated and adopted American ways leaving behind their ethnic identities. There was an, "apparent fondness for public display of physical fitness... that incorporated the putative symbols of nationhood-- flags, anthems, unified movements like marching... cultural artifacts that appear to conform our understanding of nation making..." (p.419). The use of national symbols and cultural artifacts during sporting events is a great tool in the process of developing national identity (Gagen, 2004).

\subsection{Learning from globalization: The role of education and sports in the process of forming national identity in the Peruvian society}

The Peruvian school system is based on the philosophical conceptions in education of Jose Antonio Encinas, which promotes revolutionary educational excellence and social leadership. From this perspective, the school system must be prepared to efficiently perform the technical, pedagogical, and philosophical aspects of education within the context of Peruvian culture. Education must serve as a transformative, formative, and socially-oriented agent that strives for the development of better generations. Therefore, educators are responsible for the formation of more integral future generations. Only in this way can education play a revolutionary function in society: never forgetting that education is the number one critic of a nation's current system (Peruvian Ministry of Education, 2010).

\subsection{Forming a Peruvian National Identity: Historical context}

Identity is defined as an individual's subjective understanding of the self. However, an adequate definition of the self is one that considers inclusively both an individual's thorough 
understanding of the self in combination with those of the group (Rottenbach \& Espinosa, 2010; Vignoles, Regalia, Manzi, Golledge \& Scabini, 2006). According to social psychologist Henri Tajfel (1984), social identity is defined as the part of a person's understanding of himself that derives from his awareness of belonging to a community (also see Rottenbach \& Espinosa, 2010). Rotenbach and Espinosa argue that national identity is an extension of the concept of social identity. According to the research, while social identity merely responds to the biological needs of human existence, national identity demands the existence of a sociopolitical structure. This organized structure is the nation-state (Perez, 1999; Rottenbach \& Espinosa, 2010). Herranz and Babase (1996) suggest that nation-states are strengthened by cultural traditions, artifacts, and ceremonies that individuals need to construct a national identity. Therefore, history and folklore provide collective knowledge and behaviors that let individuals reinforce their national identity (Herranz \& Babase, 1996; Rottenbach \& Espinosa, 2010).

Rottenbach and Espinosa (2010) say that, "it is reasonable to believe that Peruvian national identity is based on the collective memory of certain stable characteristics that separate what it means to be Peruvian in differentiation to what it means, for example, to be Chilean, Bolivian, American, or European." (p.152). This set of defined characteristics that separate one group from another help an individual's collective memory to develop a sense of belonging. For example, in Peru, the quality and diversity of the nation's gastronomy, as well as the historic achievements of the Incas are remarkable examples (Rottenbach \& Espinosa, 2010).

The research suggests that in nations like Peru, characterized by diversity and migration, it is possible to observe the difficulties encountered in the process of forming a united and inclusive state. Nonetheless, analysts argue that collective memory defines both purpose and goals, attributing unity of meaning to the group and allowing for a better understanding of the culture's past, present and future (Rottenbach \& Espinosa, 2010).

Even though Peru's economy has boomed in the past decade bringing extreme poverty levels down from $23 \%$ in 2002 to $11.5 \%$ in 2009 , there are still inequalities amongst social classes, ethnic groups and genders. A Peruvian born in the rural highlands is four times more likely to be poor and three times more likely to not finish secondary education than someone from Lima. This geographical and economic gap makes Peru a centralized nation, where Lima is fantasized as the epicenter of Peruvian society, business, and life opportunities. In this context, national local identities are lost and replaced by the fantasy of becoming a member of the capital, Lima Metropolitana (Alarcon, 2010). Alarcon exemplifies this phenomenon by telling the story of a famous radio announcer from Arequipa (south of Lima) who leaves his city to go to the capital, "In 1956, the legendary announcer Óscar Soto Solis left Arequipa to try his luck in the capital, and Radio Continental, the most powerful station in southern Peru, was suddenly without its emblematic voice.” (p. 12). This happens in Peru often, where many citizens think that life in Lima will provide them more opportunities and a richer life; they leave their cities, the provinces, only to later find out that Lima is a city of racism, 
discrimination, and exploitation (Alarcon, 2010). Alarcon writes, "It was in 1960 that Soto Solis returned from Lima - the hometown legend never had much success in the capital." ( $p$. 13).

National identity in Peru is a historically complex issue. According to Sanchez-Leon (1994), it is a problem that started during colonization and that is still present in South American societies, mostly noticeable in the Andean communities of Peru and Bolivia. He says, "This is a history that began tragically when the Spanish conquered the Incas almost five centuries ago, dividing the Empire, creating a state of civil war, and initiating centuries of abuse and oppression" (p.144). Peruvians lost their land, and with it, their sense of belonging. Sanchez-Leon explains. "To this day, Peruvians--in their complex makeup-still do not know whether to side with the conquerors or the conquered. As mestizos, in any case, they feel the pain of the defeated. Defeat has come to establish itself as a kind of collective identity." (p. 145).

\subsection{Equity in early education in Peru: Developing a nation in poverty}

The purpose and goals of a nation define the nature of the group. A better understanding of the culture's past, present and future can contribute to the development of a stronger sense of national identity and nationalism. The research suggests that one of the most effective ways to engender national identity is during early education (Rottenbach \& Espinosa, 2010). The quality and equity of early childhood learning programs are key elements in a nation's social development (Moromizato, 2006).

Moromizato (2006) analyzes the quality and equity in Peruvian education. She says that, “... the reflection on the child has evolved so as to accommodate positions that express concern for the whole, integral, and harmonious development of children... the child is seen as a subject with rights and not only as economic investment in the future." (p.187). Moromizato suggests that because of the high cost of preschool education in Peru, childhood care and preschool education (Education Inicial) are mostly limited to private schools, and to the areas where there is economic growth; making it an unfair system for the national regions with limited resources.

However, in an attempt to make education more democratic and available to the poor, some non-conventional programs have been created in the less privileged parts of the country. These programs are as structured and efficient as their conventional counterparts, and in many cases, surprisingly cheaper. These alternative programs offer a wide range of secondary programs that help with basic needs such as nutrition and health as well as with other, more complex, national problems such as education and social conflict. One of these programs is Wawa Wasi. Wawa Wasi is implemented and funded by the Peruvian Ministry for Women and Social Development (MIMDES-Peru). Wawa Wasis are currently helping over 40,000 children in Peru between the ages of 6 months and 4 years of age that live in extreme poverty. According to Moromizato (2006), “ The Wawa Wasi program seeks to foster the human and 
social development of children.” (p. 188). This program's strategy follows the guidelines established in the National Action Plan for Children 2002-2010, which emphasizes equal opportunity for all. It also gives priority to children as subjects with rights and sustainers of development, increases interest in the child and its right to participate, and sees the family as the fundamental institution for the development of the human being (Moromizato, 2006).

\subsection{The role of sports in social development and Peruvian identity}

Although there is limited research on the influences of sports on social development new studies outline some of the ways that sports can be used to promote social development. Levermore (2008) suggests that, "sports related activities can reach communities and promote development in ways that politician and government agencies cannot (p.184). Levermore argues that physical education and sport activities, under the umbrella of an integral educational system, may contribute to the further development of better communities. Furthermore, Weiss (2007) says, "There is a positive correlation between sports, education, and social development (p.436). Weiss suggests that adopting a developmental perspective towards understanding youth participants' experiences in sports is fundamental for a system's success in the areas of policy making and policy practice.

According to Panfichi's and Vich's analysis of the situation of Peruvian sports, "Historically, Peruvian sports have survived with limited resources, almost no support from the government, an unstable flow of income, and sporadic private sponsorship" (p. 287). This situation created an unbalanced reality between the expectations of society and the difficulties of organizing successful sports programs within the context of generalized poverty. Moreover, this scenario becomes even more difficult when the government has become increasingly corrupt and what little resources remain have gone toward the development of the military (Panfichi \& Vich, 2004).

Social, political and economic--and sports subjugated to those three variables-- unrest in Peru have delayed not only the nation's development in the global scene but also the development of a cohesive national identity. The story began, tragically, when the Spanish conquered the Incas almost five centuries ago dividing the Empire, creating a state of civil war, and initiating centuries of abuse and oppression. This is the point in history where natives, and later mestizos, lost their land and identity, and when they felt defeated for the first time. Therefore, defeat in Peru has become a form of collective national identity (Sanchez-Leon, 1994).

To top it off, during the 1980s the nation's violence increased exponentially with the emergence of the Shining Path. This terrorist organization was a Moist inspired radical armed movement that has been born in the Andes that had finally reached the capital, Lima. The Shining Path, originally a leftist political party, broke off its ties with traditional political means and opted for armed action against the state. Panfichi and Vich (2004) described the Shining Path as a movement that, “... sought a true and communist society under the Authoritarian rule of its leader, Abimael Guzman” (p.289). But Guzman's ideal brought only tragedy and horror to the 
nation, devastating cities through unforgettable terrorist actions (Panfichi \& Vich, 2004).

\section{Conclusion}

Globalization is a reorganizing force. This reorganizing of theories and methodologies is the result of linking economic and social change to the ways societies develop and transmit knowledge in the technological world. The future of nation-states is interdependent. Therefore, the success of a culture in the globalized world depends on its functional inter-connectivity with other systems (Carnoy \& Rhoten, 2002).

Current studies in international education believe that citizenship education, and the rhetoric behind the formation national identity, should be reformed to meet a nation's cultural diversity so that it includes the traditions of the sub-cultures that shape it. Moreover, citizenship and citizenship education should be molded to equally embrace the cultural rights of citizens from diverse racial, linguistic, ethnic backgrounds (Banks, 2008). Therefore, if educational reform is successfully implemented to fit the needs of globalization, it can contribute to both the theory and the praxis of education in the world. The result of this reorganization brings about a more dynamic approach, which is constantly re-conceptualizing education and helping to bridge cultural differences (Crossley, 2008).

However, developing a united culture, with a strong national identity, in poverty is difficult. The high cost of preschool education in Peru, child care, and preschool education are mostly limited to private schools and to the areas where there is economic growth, making it an unfair system for the national regions with limited resources.

Although the social, political, and economical unrest in Peru has delayed not only the nation's growth in the global scene but also the development of a cohesive national identity, research suggests that sports can be an effective tool to promote social development in ways that governments cannot achieve overtly. Therefore, based on the theory analyzed above, it is possible to infer that physical education and sports activities, under the umbrella of a globalized, integral, multicultural, and inclusive educational environment, can contribute to the further development of a more cohesive Peruvian national identity.

\section{Bibliography}

Alarcon, D. (2010). My father's game. Has

YouTube ruined soccer? A memoir. The New Republic, 12- 13.

Banks J.A. (2008). Diversity, group identity, and citizenship education in a global age. Educational Researcher, 37, 129-139.

Carnoy C., \& Rhoten D. (2002). What does globalization mean for educational change? A comparative approach. Comparative Educational Review, 46, 1-9.

Crossley, M. (2008). Bridging cultures and traditions for educational and international development: Comparative research, dialogue and difference. International Review 
of Education, 54, 319-333.

Flores, R., \& J.D., Zamora (2009). La educacion fisica y el deporte como medios para adquirir y desarrollar valores en el nivel de primaria. Revista Educacion, 33.1, 133-143.

Gagen, E.A. (2004). Making America flesh: physicality and nationhood in early twentieth-century physical education reform. Cultural Geographies, 11, 417-442.

Gatzeman, T., Schweizer K., \& Hummel A. (2008). Effectiveness of sports activities with an orientation on experimental education, adventure-based learning and outdoor education. Kinesiology, 2, 146-152.

Gestion Pedagogica (2010). Ministerio de Educacion de Peru. http://www.minedu.gob.pe/ Gutek, G. (2006) American Education in a Global Society. (2 ${ }^{\text {nd }}$. Ed). Waveland Press: IL.

Herranz, K. \& Basabe, N. (1999). Identidad nacional, ideología política y memoria colectiva. Psicología Política, 18, 31-47.

Levermore, R. (2008). Sport: a new engine of development? Progress in Development Studies, 8.2, $183-190$.

Moromizato, R. (2006). Quality and equity in early childhood care in Peru. Review of Education, 52, 185-199.

Panfichi, A. \& Vich, A. (2004). Political and social fantasies in peruvian football: The Tragedy of Alianza Lima in 1987. Soccer and Society, 5.2, 285-297.

Rottenbacher, J.M., \& Espinosa, A. (2010). National identity and historic collective memory in Peru. An exploratory study. Revista de Psicologia 28.1., 147-174.

Sanchez-Leon, A. (1994). The history of Peruvian women's volleyball. Studies in Latin American Popular Culture, 13, 143-153.

Tajfel, H. (1984). Grupos humanos y categorías sociales: estudios de psicología social. Barcelona: Herder

Andean Air Mail \& PERUVIAN TIMES (2010). UN: Extreme poverty declines but inequality persists. Retrieved from http://www.peruviantimes.com/11/un-extreme-poverty-declines-but-inequality-pers ists/8048/

Vignoles, V., Regalia, C., Manzi, C., Golledge, J. \& Scabini, E. (2006). Beyond self-esteem: Influence of multiple motives on identity construction. Journal of Personality and Social Psychology, 90.2, 308-333.

Weisner, T. (2009). Culture, development, and diversity: Expectable pluralism, conflict, and similarity. Ethos, 37, 181-196.

Weiss, M. (2007). "Field of Dreams:" Sport as a context for youth development. Physical Education, Recreation and Dance, 79.4, 434-449. 